\title{
11. UNCERTAINTY, “IRRATIONAL EXUBERANCE” AND THE PSYCHOLOGY OF BUBBLES: AN ARGUMENT OVER THE LEGITIMACY OF FINANCIAL REGULATION FOR BOUNDED RATIONAL AGENTS
}

https://doi.org/10.36592/978-65-81110-11-6-12

Ramiro de Ávila Peres ${ }^{1}$

\section{Introduction: Greenspan's uncertainty and crisis prevention}

The causes of banking crises and business cycles are actually well known to economists, despite the lack of consensus on what to do about it (Schefczyk, 2016: 266). In the case of the 2007-2008 crisis, monetary expansion (justified to counteract the negative effects of the 9/11 and of the dot-com bubble on the real economy) and government incentives would have led to a housing bubble, funded by a largely unregulated market (including a shadow banking system) of mortgage-backed securities (MBS), secured by derivatives such as credit default swaps (CDS). High leverage and overly permissive regulation would have made the banking system vulnerable, and transaction complexity made it difficult for supervisors and regulators to assess the risks (MacMillan, 2014: 56). Finally, after Lehman Brothers collapsed in September 2008, the government had to provide liquidity to the system and so invested in institutions under risk of bankruptcy (the infamous bail-out) as the economy went into recession².

\footnotetext{
${ }^{1}$ Bacharel em Direito e Doutor em Filosofia pela UFRGS, analista do Banco Central do Brasil. E-mail: ramiro.peres@ufrgs.br. Endereço: R. Joaquim Nabuco, 320, Porto Alegre/RS. Orcid: 000o-00029376-2105

2 As an example of the 'catastrophic' character of the Crisis, we can cite this description:

"[Northern Rock] was the first symptom of the global crisis, which reached the next level with the very similar collapse of Bear Stearns in March 2008, followed by the crash that really took the entire global financial system to the brink, the implosion of Lehman Brothers on 15 September. Because Lehmans was a clearing house and repository for many thousands of financial instruments from around the system, suddenly nobody knew who owed what to whom, who was exposed to what risk, and therefore institutions were likely to go next. And that is when the global supply of credit dried up. I spoke to bankers at the time who said what happened was supposed to be impossible, it was like the tide going out everywhere on Earth simultaneously. People had lived through crises before - the sudden crash of October 1987, the emerging markets crises and the Russian crisis of the 1990s, the dotcom bubble - but what happened in those cases was that capital fled from one place to another. No one had ever lived through, and no one thought possible, a situation where all credit simultaneously disappeared from everywhere and the entire system teetered on the brink. The first weekend of October 2008 was a point when people at the top of the global financial system genuinely thought, in the words of George W. Bush, 'This sucker could go down. ' RBS, at one point the biggest bank in the world according to the size of its
} 
It would have been, therefore, much more economical 3 to have adopted restrictive previous measures, such as increasing capital requirements for the banking sector, or even - more unpopular - raising interest rates, in order to avoid the crisis; in particular, it would have been better for the worst-off population. Why did Greenspan not do it? After all, Central Banks are regulatory and monetary authorities: their main role is to maintain economic and financial stability, by controlling the amount of money in the economy, through government bonds transactions. Also, they operate as "banks of banks", as lenders of last resort to provide liquidity to the financial system; and many Central Banks also play a special role in regulating and overseeing the financial system. These three functions (monetary authority, liquidity provider, and financial system regulator) have grown in response to the Crisis - so attracting the label of overmighty citizen (Tucker, 2018: 391).

The problem is that he didn't know a bubble was about to burst, nor that it would be harmful for the real economy. since the real estate bubble and the following crash could not be predicted, he could not have avoided it (Greenspan, 2013, 10). No one can guess when a "bubble" begins, nor when it ends; this is a consequence of the (weak) Efficient Markets Hypothesis. Bubbles happen because of the emotional "irrational exuberance" of investors' behavior, which causes the boom and bust of business cycles: first, bullish markets make investors greedy and uncareful, concerned with short-term profits; then they are succeeded by a crash that spreads panic, and a bearish environment of increased risk-aversion yields recession - to be overcome by monetary stimulus (Greenspan, 2013: 89)4.

\footnotetext{
balance sheet, was within hours of collapsing. And by collapsing, I mean cashpoint machines would have stopped working, and insolvencies would have spread from RBS to other banks - and no one knows what that would have looked like or how it would end." (Lanchester, 2018)

3 The bail-out alone would have cost the US government U\$700 billion (Stiglitz, 2010). But this does not represent the impact on economic growth; the average annual growth of the Gross Domestic Product (GDP) was 2.99\% between 1998 and 2007, but only 0.73\% in the following five years (2008: -0.31\%, 2009: -3.1\%). Global GDP growth was $4.3 \%$ in 2006 and $4.2 \%$ in 2007 , falling to $1.7 \%$ in 2009. Data from the World Bank, available at: <https://data.worldbank.org/indicator/NY.GDP.MKTP.KD.ZG> .

4 For Greenspan, the role of the FED is not to prevent bubbles, but to prevent them from damaging the real economy (Greenspan, 1996). During the "Great Moderation", it worked well and helped the economy to overcome financial crashes (e.g., the $1987 \mathrm{crash}$, the 98 and 99 crisis in eastern markets, the dot-com bubble of 2000...). For Krugman (2009), the optimism resulting from the 'Great Moderation' may explain the hubris that prevented the authorities from adopting a proper regulatory framework and anticipating the crisis of 2007; or, as Greenspan himself puts it: "What do we get by being very successful in forecasting? And I say a bubble. In fact I think the evidence is conclusive that a necessary and sufficient condition for bubble is a prolonged period of economic stability, stable prices, and therefore low risk spreads, credit-risk spreads." (Fox, 2014)
} 
It is true that Rajan (2006), then Director of the IMF Research Department, pointed out the risks of securitization and the possibility of a systemic crisis; similarly, Roubini (2006) argued that the FED should intervene on the real estate bubble, and even raise interest rates - but like others, they were considered to be overreacting. Part of the problem here is how to deal with peer disagreement; Greenspan (2013) complains that, although there are always researchers warning about a collapse (and eventually, they are right), there are at least as many scholars arguing otherwise, too.

Moreover, regulators are not in a better situation for assessing risks than investors. Since market participants supposedly know their own risks better than regulators (a kind of informational asymmetry), an intervention (except to ensure lawenforcement) would imply unjustified paternalism. That seems to be a good point: according to Joseph Raz's (1986: 53) normal justification thesis (NJT), an authority is justified if one is more likely to attend to the applicable reasons by abiding by the authoritative directives than by pursuing those reasons directly, by oneself. So, if regulators don't know better than regulated agents, NJT wouldn't apply to them.

However, a regulator does not have to be conceived as a paternalistic authority, only necessary to correct a subject's deviation from rationality; as Raz himself points out, NJT can have a wider interpretation. In this article, we provide an objection to Greenspan's argument. First, we sketch a brief decision theory under uncertainty for bounded rational agents applied to financial investors, and show how it can unsurprisingly lead to bubbles - despite the efficient markets hypothesis. We claim that crises don't require a defective reasoning such as the "irrational exuberance" our usual bounded rationality might be enough to provide the kind of "self-fulfilling prophecy" observed in the rise and fall of assets values. Even so, they can be avoided, and uncertainty is no excuse for delaying prudential measures; given the possibility of grave externalities, authorities are justified in adopting measures to ensure investors behave in a prudent way - otherwise, they may have insufficient incentives to know better their own risks. 


\section{Decision theory, efficient markets and financial bubbles}

\subsection{Decision-making under uncertainty}

Let's start with a weak subjectivist notion (i.e., that says nothing about the agent's ends) of rationality as coherence between means and ends. This notion applies to decision problems characterized by: A) an agent; B) a set of mutually exclusive actions she can take; C) a set of states of affairs (possible worlds). The decision involves a "learning rule", which defines how the agent represents states of affairs: a) begins with an a priori probability distribution that assigns a corresponding value to each possible world; b) as she receives new information, the agent updates its probability distribution by conditionalization (by using an appropriate rule, such as Bayes' theorem) - resulting in a posteriori probability distribution (Bostrom, 2014: 10). Furthermore, the agent needs a decision rule, which defines how she values states of affairs; if she does it consistently, we can assign her a utility-function - a complete, continuous and transitive order of preferences associating each a state of affairs with a quantity representing its corresponding "desirability". By deciding, she selects the action with the greatest utility; for this, it must compute: a) for each possible world $M$ and each action $A$, the respective a posteriori probability $p$ of reaching the possible world $M$ conditioned to the choice of action $A$; b) for each possible world $M$, the product ( $p \times u$ ) of that probability $p$ and the corresponding utility $u$; $c$ ) for each share, the sum of each of these products5 (Bostrom, 2014: 11).

Now, let's clarify what we mean by uncertainty - a vague and ambiguous term. We will treat it as opposed to the concept of information and also adopt here Knight's (1921: 46) distinction between risk and uncertainty (so-called "unknown risk"). In the latter sense (used by, e.g., decision theory under complete ignorance) one does not have an adequate definition of the probabilities of possible states of affairs; we can also call it ambiguity, because the probability distribution over possible worlds is ambiguous (i.e., it may have more than one distinct value) in this case. Even then, uncertainty can increase if the agent is unaware of every possible state of affairs or even of her own utility function. One of the main sources of this "greater" uncertainty

\footnotetext{
5 That is, the expected utility of an action A is the average of the corresponding utility of the possible
} worlds, weighted by the corresponding probability (conditioned to action A) of each of them. 
is the existence of other decision-makers, trying to predict each other's decisions and to react to them; this yields what social scientists call reflexivity: a feedback loop between the environment and the way investors perceive it (Soros, 2008) .

Applying this reasoning to the debate over financial bubbles and crashes, one can argue they should be impossible in an efficient market, where the price of an asset includes the value of all available information, including about its future value: since rational investors can apply backward induction reasoning and anticipate its devaluation, they would not buy a security offered at an inflated price. So, if we observe bubbles, it is either: a) because investors are "exuberantly" irrational (i.e., our premise is wrong), or b) because the argument is invalid, and markets cannot be so informationally efficient as to prevent bubbles and crashes; of course, (a) and (b) do not exclude each other. These explanations yield distinct recommendations: if the problem is (a), an inherent limitation of our rationality, we might be tempted to appeal to an expert or paternalistic authority - someone who knows better than ourselves, or who can correct our deviations from reason. But in the case of finances, one can reply that authorities are defective reasoners, too: they are seldom epistemically better placed than investors, who have enough skin in the game to want to avoid reasoning failures by themselves (actually, they supposedly teach each other theses failures by profiting from them). However, if (b), then markets are fragile to some special dynamics (they are prone to self-fulfilling prophecies, or incur in negative externalities), then their institutional design might be improved by adding a supervising authority.

\subsection{Bubbles I: exuberant bounded rationality}

First, we must beware: the model of an agent sketched supra is unrealistic. After all, it is trivial that any physically possible agent has limited processing capacity - and this limitation leads to satisficing (instead of optimizing) behaviors with procedural

\footnotetext{
${ }^{6}$ This is one possible explanation for why social processes are not, as opposed to phenomena of classical physics, ergodic processes where the statistical properties of a 'set' of observations in a given period tend to be equivalent to the statistical properties of the system over time. It explains the commonplace that 'there are no general laws' for social phenomena (at least for non-ergodic ones). According to Peters (2011), since Bernoulli in 1738, expected utility theory (and with it many economists) presupposes ergodicity - which would allow economists to (a) model states of affairs by a normal distribution and, so using the central limit theorem, apply the mean as a measure of tendency, and to (b) treat the economy as an exact science.
} 
features (Barros, 2010). Consequently, we are also logically incomplete, which implies we cannot conceive all possible states of affairs; this entails what Donald Rumsfeld called "unknown unknowns". That is an empty notion for an unbounded rational agent: in a logically complete epistemological system, "I do not know that I do not know that $p$ " implies "I know that p." (Binmore, 2009: 139) 7 Instead, our incompleteness allows for our logical modesty, our potential to know we have inconsistent propositional attitudes - such as Sorensen's (2001: 125-126) ability to claim to have inconsistent beliefs ${ }^{8}$.

Our reasoning procedures, cognitive abilities and emotions (such as fear, pain, pleasure, greed...) include different processes operating in parallel and were not designed as a consistent system - in fact, they did not even evolve synchronously. This explains, e.g., so-called weakness of will: when Ahab asks to be tied to have his leg severed, he does so because he knows that his current preferences in relation to his future states conflict with the immediate preferences he will have as soon as the surgery begins (Schelling, 1983). Similar conflicts may occur in cognition; Sorensen (2001: 38) dubs this set of distinct processes "specialized homunculi who work like idiot savants." But if these homunculi cannot be submitted to a single system with the last word (so analogous to a "dictator" in social choice theory), then the situation is like that of a society with voters with distinct preferences (as argued by, e.g., Dennett, 2018), where the observation of inconsistencies is an expected consequence of Arrow's (1950) theorem.

That is what we call bounded rationality - which is not a complete departure from the model of the rational agent; there are empirical confirmations that, under normal conditions, we do approach the rational model (in the sense that subjects

\footnotetext{
7 This derives trivially from the corollary that the agent knows all the logical space. Even in an epistemology logically weaker, incorporating only the axioms of factivity $(\mathrm{Kp} \rightarrow \mathrm{p})$ and reflexivity $(\mathrm{Kp}$ $\rightarrow \mathrm{KKP}$ ), the usual interpretation of 'unknown unknown' is trivially false: an agent cannot be mistaken about whether a proposition $p$ belongs to its belief system or not - it is impossible that, between 'Kp' and ' $\sim$ Kp', one chooses the false alternative.

${ }^{8}$ By assuming that mistakenly assessing consistency implies being inconsistent (i. e., that if $p$ is a consistent proposition, then ' $p$ is inconsistent' is an inconsistent proposition), then one can provide an argument similar to the Liar's paradox: let $p=$ 'it is impossible to have inconsistent beliefs'; thus if Sorensen (2001: 125) believes in not- $p$, he believes in an inconsistent belief - but this implies that $p$ cannot be true.

Why didn't Sorensen's belief system collapse? After all, one can derive anything from a contradiction. The explanation may point again to the incompleteness of this system: either the inconsistency cannot be discriminated and is locally restricted (as in the case of the logic student who does not know whether he made an error in a test - Sorensen, 2001: 157), or it stems from two distinct cognitive processes running in parallel, and the inconsistency is solved, when necessary, in "execution time" by the conscious subject.
} 
behave as if they are consistently maximizing a utility function), and deviations can be explained as performance errors (that subjects would correct after reflection), or accommodated in extensions of the theory (Gintis, 2009: 23). Also, even if this model is not always descriptively accurate, one can argue it provides a good normative theory. One can observe that trying to accurately and consistently assign probabilities, even when they are not available, is a good policy leading to superior outcomes, particularly in the activity of making predictions - as revealed by the emergence of "super forecasters" in forecasting competitions (Tetlock \& Gardner, 2017).

On the other hand, economists are tempted to explain market failures as explicit deviations from this model - i.e., as caused by a defective way of reasoning, as connotated by Keynes's animal spirits or Greenspan's (2013) irrational exuberance. And we may be particularly prone to some of these deviations: when operating in contexts other than the ones where they evolved as an optimal solution, some of our heuristic reasoning procedures entail predictable failures - so-called cognitive bias (Kahneman, 2012). They are like instincts: for example, pilots need to be trained to hold the instinct to pull back on an airplane's control wheel during a stall - lest they would slow the air speed above the wings and cause the plane to lose altitude even more quickly (Lo, 2013: 631). Similarly, one could argue that akrasia and incontinence derive from reasoning patterns, such as short-term thinking and hyperbolic discount of future, that were optimal in our evolutionary history (Holton, 2011: 69); combine it with the herd behavior (explained by our communitarian past) observed in financial booms and panics, and we have a folk psychology theory of financial bubbles.

Supposedly, if not for this primitive way of reasoning, there would be no crises. Thus a good deal of debate focus on up to what point can financial markets improve our reasoning (it encourages investors to make a profit by aggregating their information to the market) or, instead, amplify our mistakes: "Stock prices contain lots of information. Markets, Friedrich Hayek argued, are the best aggregators of information known to man. Yet mixed up amid the information in security prices is an awful lot of emotion, error, and noise." (Fox, 2011) In the following section, we will contend this argument: uncertainty might be enough, for bounded agents in strategic interactions, to lead to bubbles; we don't need irrational exuberance to explain it. 


\subsection{Bubbles II: paradoxical informational efficiency}

According to the strong version of the Efficient Market Hypothesis (EMH), since rational investors quickly exhaust all possible arbitrage opportunities, all price oscillations are random. Even if a market has irrational individuals, their random errors should "compensate" each other, so that the market trend would end up determined by a minority of well-informed rational individuals (Sunstein, 2006: 106).

Strong-EMH would imply the impossibility of bubbles - hence Quiggin (2010) calls it a zombie idea, due to the large number of counterexamples 9 . However, in its weak version - uncontested even by Quiggin (2010: 37-38) - EMH states that prices reflect all past publicly available information and does not imply the impossibility of a bubble, but just the impossibility of an agent reliably predicting it. This version is resistant to counterexamples; after all, if someone trustworthy predicted a bubble, a responsible authority would prevent it. Sorensen (1988: 110) argues that weak-EMH so becomes a kind of blindspot - a thesis that, even if true, cannot be contained in some propositional attitudes of investors: it is only true insofar as some act without believing in it, as investors spend resources seeking new information that later, through their investments, will be added to the market (in the same sense: Lomasky, 2011: 150).

The dynamics of bubbles are like Keynes's "beauty contest" example, in which the participants try to guess which candidate will be the most voted, and its structure is that of a guessing game or race to the bottom ${ }^{10}$ (Talwalkar, 2014). Even if there are rational individuals who recognize it, some of them, rather than shorting the bubble

\footnotetext{
9 One should note informational efficiency should only apply to thick markets, with "homogenous products, large numbers of buyers and sellers who regularly engage in repeated transactions, transparent pricing and, ideally, forward markets for purchase or delivery at future dates." (Quiggin, 2018: 217) This restriction, therefore, would exclude real estate markets, with rigid prices and no possibility of short selling assets (Millan, 1977).

${ }^{10}$ In a classic race to the bottom, players must pick an integer within a finite range; the winner is the one who picks the number closest to the antecedent to the average (rounded down) of the other 'bids' which is the result of the game. By backward induction ('If the mean of the group, with the exception of $x$, is equal to the number $n$, then $x$ must answer $n-1$ '), it turns out that the dominant strategy is to choose the smallest number in the range; however, in real race-to-bottom examples, outcomes never coincide with this - especially if the promised reward is a function of the game result. Imagine, e.g., that the range is $[0,100]$ and that the reward will correspond to four times the result, in money, divided among the winners; thus, backward induction implies the answer 'o' - therefore, it remunerates rational agents with no prize at all!

Our point is not only the commonplace that real individuals do not behave as rational agents, nor that in iterated games it might be rational not to follow the perfect sub-game equilibrium (given the common knowledge of the possibility of not following) - but also that a competitive environment may select individuals who behave accordingly.
} 
asset to bet on its burst, might assume that they will be able to profit even more by "buying low and selling high" - and some of them will, even if it is risky. More naïve investors may try to fool themselves about the risk by relying on the execution of stoploss orders to withdraw before the downfall - so neglecting that too often an asset's value may fall abruptly and cross the corresponding threshold before the order's execution (Mandelbrot \& Hudson, 2008: 23).

The premise of common knowledge of rationality generates here a paradox in the backward induction, such as in the centipede game and in the iterated prisoner's dilemma (Gintis, 2009: 110; Sorensen, 1999: 279) - where even rational agents may deviate from the dominant perfect sub-game equilibrium, given the positive likelihood that others (doing the same reasoning) will also diverge from this solution. In philosophy, the classic example of the backward induction paradox is the surprise test $^{11}$ : a student argues there cannot be a surprise test, since he knows the days of the classes and can use backward reasoning to prevent any surprise. Seeing the student's argument, the teacher may surprisingly apply the test the following Wednesday - so the prediction "there will be a surprise test" turns out to be true (so it is not contradictory). However, this proposition cannot be object of common knowledge between the student and the teacher (Gintis, 2010: 171); it is what Sorensen calls blindspots.

The "irrational exuberance" is not a condition for this. On April 23, 2013, the Associated Press twitter account was hacked and exhibited for some minutes a fake news about an explosion at the White House; few people saw this, and possibly no one believed it - investors access many sources of information. But many investors liquidated their positions, with the help high-frequency trading (HFT) algorithms (which increase market efficiency), and the Dow Jones plunged, yielding losses estimated at U\$ 1 trillion (Kirilenko \& Lo, 2013). There were no panicking investors afraid of war; actually, even if a rational trader does not assign a high probability to an

\footnotetext{
11 "A teacher announces that there will be a surprise test next week. A student objects that this is impossible: "The class meets on Monday, Wednesday, and Friday. If the test is given on Friday, then on Thursday I would be able to predict that the test is on Friday. It would not be a surprise. Can the test be given on Wednesday? No, because on Tuesday I would know that the test will not be on Friday (thanks to the previous reasoning) and know that the test was not on Monday (thanks to memory). Therefore, on Tuesday I could foresee that the test will be on Wednesday. A test on Wednesday would not be a surprise. Could the surprise test be on Monday? On Sunday, the previous two eliminations would be available to me. Consequently, I would know that the test must be on Monday. So a Monday test would also fail to be a surprise. Therefore, it is impossible for there to be a surprise test." (Sorensen, 2014)
} 
unlikely information from an unconfirmed source, in a strategic context, she will minimize her exposure to risks if she assigns a sufficiently large probability to the hypothesis $H$ : "a large number of other agents will minimize their exposures". Therefore, nobody needs to believe in the extraordinary information; one must only assign a sufficiently high probability to $H$ - which thus becomes a self-fulfilling prophecy.

\section{Authorities, incentives and prudence}

Thus, our point is that, even if a regulator's information were only a subset of the bank's information (i.e., if information asymmetry were unilateral), and supposing economic agents are not irrational, the regulator could still justifiably act over their incentives. There is a problem analogous to a prisoner's dilemma here: firms have no incentive to unilaterally classify assets they already hold at a higher risk level, as it would entail a competitive disadvantage for the company (at least in the short-term, which is the scenario where executives take their decisions). As Greenspan mentions concerning the acquisition of MBS: "Financial firms were thus fearful that should they retrench too soon, they would almost surely lose market share, perhaps irretrievably." (Greenspan, 2013: 71) Nor can one expect auditing companies to encourage this behavior: since they audit firms on an individual basis, they seldom require a client to take a more conservative stance than the rest of the market (otherwise, such a client would likely complain and move to a competitor).

This drives the dynamics of the bubble: the asset value tends to keep rising until a set of investors gets rid of their positions (by fear of others acting earlier), so precipitating its fall and the following burst. That's why regulators are necessary to guarantee that the agents disclose their risk perceptions and remain prudent in the case of lack of information. But contrast this with Greenspan's argument:

A century ago, inspectors could evaluate loans individually and make judgments about their soundness. But in the contemporary global lending environment, how can an American bank inspector assess the creditworthiness of, say, a loan to a Russian bank, and therefore the bank's loan portfolio? This, in turn, would require assessing the Russian bank's counterparties and the counterparties of these counterparties, all to verify the soundness of a single loan. In short, neither a bank inspector nor a rating agency is able to form a judgment. To be certified, what depth is required, in the endless layers of inspection? (Greenspan, 2013: 112). 
Usually, if an institution were to give a loan to any client without having information on her ability to pay (i.e., her credit default risk), the transaction would be considered very risky. Why should it be different for the Russian bank? Greenspan introduces this example shortly after recounting his personal experience in investment banking as a banker and economist, so displaying he had practical experience; but his argument appeals more to the viewpoint of business and trading professionals (who have less aversion to uncertainty) than to the control and risk management area (which is biased towards loss aversion). This suggests he might suffer from a bias dubbed cognitive capture by Stiglitz (2010, Ch. 6, n. 57), where a decision-maker is prone to emphasize features associated with his own background and culture and to neglect insights from culturally different viewpoints. In this line, Tucker (2018: 17) remarks that one of the factors in the crisis was that Central Banks usually favor more prestigious areas and immediately impactful (such as monetary policy) rather than less visible ones (such as financial supervision).

One can only trust that "institutions know what they do" if they can reliably signal it - presenting information that justifies their risk assessments; if we do not have information enough to judge it, then the default conclusion is that the contract is risky. In the absence of regulation, agents often have incentives to omit information and to take more risk than it would be socially optimal; these amount to informational constraints undermining the communication and coordination role that economists attach to the market (Myerson, 2008: 339). If one can see regulatory norms as transaction costs burdening economy, the same reasoning can be applied to distrust and risks deriving from the lack of regulation.

Adequate risk assessment does not require the ability to precisely predict the future; but it does demand specialized knowledge and active search for information. Accounting standards and supervisory practices so end up having a performative effect (Walter, 2015: 25-26): not only they set standards for cognition (for justified judgments about an agent's assets value), but also encourage ${ }^{12}$ some behaviors from

\footnotetext{
12 This refers to the departure, in the last decades, from accounting standards for asset valuation associated with the principle of prudence (such as accrual) and with estimates based on historical series (an observable and objective factor, albeit limited) in favor of the accounting notion of fair value; it led to unusual situations before the crisis: Goldman Sachs estimated that AIG owed $\$ 5.1$ billions in derivatives, while AIG assessed the same position at $\$ 1.5$ billion - and both were endorsed by the external audit of PricewaterhouseCoopers - PwC (Ford \& Marriage, 2018). That is, not only both institutions used different models (endorsed by the same audit) to price the very same set of assets, but they used those that optimized their own corresponding positions.
} 
managers and investors (Goodhart, 2008). In an environment with asymmetric information, adverse selection and incentives to risk taking, one is justified to react with suspicion and to implement a principle like prudence in accounting.

\subsection{Two sides of informational asymmetry}

This argument might not be appealing to a firm or its managers: from an individual point of view, their potential losses are usually limited to equity. However, even under conditions where a market is the best way to aggregate dispersed information - as in Hayek's (1996) argument, opposing the market price system to a central planner - it may not be a satisfactory way for preventing that practice from spreading and resulting in a problem for the market as a whole, and in serious negative social externalities (Quiggin, 2010: 49). So, seeing how a financial crisis affects the worse-off citizens, an authority might be justified in taking measures to prevent it, even when there is uncertainty - and it is even justified to apply measures to avoid or reduce social exposure to this risk.

Finally, we can also argue against the premise that regulators are in a worse epistemic situation than private agents; if regulatory authorities and supervisors adopt a more skeptical attitude towards the market (if they do not outsource their epistemic responsibility to the supervised entities or to rating agencies), then the informational asymmetry can be bilateral - and their epistemic situations are not comparable. Even if the supervisee is usually in a privileged position to evaluate the risks and benefits of her own company, and even if open markets do aggregate some of this private information, the supervisor may have information that the supervisee does not have about the economy. In the case of financial supervision, an authority may, e.g., aggregate private information from supervised firms - so allowing for comparisons between their business and risk management models (and even clients risk-ratings. In the case of Central Banks, they may have special macroeconomic information, too: banks may estimate what the interest rate will be in the future, but the monetary

\footnotetext{
A more optimistic example is the current awareness in finances that banks should price their expositions to contingencies due to climatic risks - e.g., crop failures, floods, droughts, extreme weather, etc. No one expressly denies the existence of such a performative effect; however, it is rare for theorists to derive the corresponding conclusion (as does Walter, 2012: 41): the choice of an asset pricing models is not only a decision about a tool to represent reality, but also about adopting a coordinated strategy in a complex environment with other participants.
} 
authority decides it; the fact that economists usually emphasize that Central Banks should be "transparent" (monetary measures should not completely surprise the market participants) and prefer stable policies to discretionary decisions just corroborates this point - it means Central Banks have information that must be disclosed to market participants.

\section{Conclusion}

Despite knowing that the market is susceptible to bubbles and to crises, Greenspan's thought that he could have done little about it: irrational exuberance is a natural fact, and regulators cannot do much about it, since they would usually know less than market participants. We have argued in the opposite direction: one doesn't need to argue for the existence of defective ways of reasoning, due to cognitive bias and psychological traits, to account for market failures. First, regulation and supervision are necessary for market participants to know better their own risks, to disclose them to other participants and to respond accordingly; second, regulators have special concerns and information that the regulated agents do not have - they have a responsibility of reducing the risk of externalities and may aggregate private information. So, the objection to Raz's NJT does not apply here: financial regulators are legitimate authorities, even if they often cannot predict what will happen.

The most important conclusion, however, is that an authority should not use this kind of uncertainty as an objection against responsibility assignment - otherwise, we will encourage something analogous to "deniability". We may draw an analogy with the markets here: they are informationally efficient because market participants have the right incentives - they actively search for information and bet according to their estimation of future outcomes, looking for the chance of ripping profits by "being first" - before the information they mined becomes common knowledge. They have no incentive to say "I could not have known". So, if we want our authorities to protect our social interests, ignorance cannot be an excuse, at least not by default; uncertainty should invite prudence, not passivity. 


\section{References}

Arrow, Kenneth. "A Difficulty in the Concept of Social Welfare". Journal of Political Economy. 58, n. 4 (1950), 328-346. doi:10.1086/256963

Barros, Gustavo. "Herbert A. Simon and the concept of rationality: boundaries and procedures". Brazilian Journal of Political Economy, 30, no. 3 (2010), 455472. doi:10.1590/So101-31572010000300006

Binmore, Ken. Rational Decisions. Princeton: Princeton University Press, 2009.

Bostrom, Nick. Superintelligence: Paths, Dangers, Strategies. Oxford: Oxford University Press (UK), 2014.

Dennett, Daniel C. From Bacteria to Bach and Back: The Evolution of Minds. New York: W. W. Norton \& Company, 2018.

Dietrich, Franz; List, Christian. "Where do preferences come from?". International Journal of Game Theory, 42, 3 (2012), 613-637. doi:10.1007/s00182-012-0333-y. doi:10.1007/s00182-012-0333-y

Ford, Jonathan; Marriage, Madison. "The big flaw: auditing in crisis". In Financial Times, August $1^{\text {st }}$ 2018. London. Available at: <https://www.ft.com/content/29ccd6oa-85c8-11e8-a29d-73e3d454535d>.

Fox, Justin. The Myth of the Rational Market: A History of Risk, Reward, and Delusion on Wall Street. New York: HarperCollins, 2009.

Fox, Justin. "What Alan Greenspan Has Learned Since 2008".Harvard Businesss Review online, January $7^{\text {th }}$, 2014. Available at: https://hbr.org/2014/o1/what-alangreenspan-has-learned-since-2008

Gintis, Herbert. The Bounds of Reason: Game Theory and the Unification of the Behavioral Sciences. Princeton, N.J.: Princeton University Press, 2009.

Gintis, Herbert "Review 2. Rationality and its Discontents". The Economic Journal, 120, n. 542 (2010), F162-F180. doi:10.1111/j.1468-0297.2009.02342.x

Goodhart, Charles. "The Boundary Problem in Financial Regulation". National Institute Economic Review, 206, 1 (2008), 48-55. doi:10.1177/0027950108099842

Greenspan, Alan. "The Challenge of Central Banking in a Democratic Society". Remarks by the Chairman of the Board of Governors of the Federal Reserve System at the Annual Dinner and Francis Boyer Lecture of the American Enterprise Institute for Public Policy Research, on December $5^{\text {th }}$, 1996. Washington, D.C.: FED. Available at: https://www.federalreserve.gov/boarddocs/speeches/1996/19961205.htm 
Greenspan, Alan. O mapa e o território: Risco, natureza humana e o futuro das previsões. Translation: André Fontenelle e Otacílio Nunes, 2013. São Paulo: Penguin, Schwarcz.

Hayek, Friedrich A. "The Use of Knowledge in Society". Knowledge Management and Organizational Design, 1996, 7-15. doi:10.1016/b978-0-7506-9749-1.50005-3.

Holton, Richard. Willing, wanting, waiting. Oxford: Clarendon Press, 2011.

Kahneman, Daniel. Rápido e devagar: duas formas de pensar. Translation: Cássio de Arantes Leite. Rio de Janeiro: Objetiva, 2012.

Knight, Frank. Risk, Uncertainty, and Profit. Boston, MA: Houghton-Mifflin, 1921.

Krugman, Paul R. The return of depression economics and the crisis of 2008. New York: W. Norton \& Company, 2009.

Lanchester, John. “After the Fall”. London Review of Books, 40, 3 (2017), 3-8. Available at : https://www.lrb.co.uk/v40/n13/john-lanchester/after-the-fall

Lo, Andrew W. "Fear, Greed, and Financial Crises: A Cognitive Neurosciences Perspective”. In Fouque, J. \& Langsam, J. (Eds.). Handbook on Systemic Risk. Cambridge: Cambridge University Press, 2013, pp. 622-662. doi:10.1017/cbo9781139151184.032

Lomasky, Loren E.. "Liberty after Lehman Brothers." Social Philosophy and Policy, 28, 2 (2011), 135-65. doi : 10.1017/So265052510000245

Mandelbrot, Benoît; Hudson, R. L. The Misbehavior of Markets: A Fractal View of Financial Turbulence. New York: Basic Books, 2011.

McMillan, John. (pseudonym). The End of Banking: Money, Credit, and the Digital Revolution. Zurich: Zero/One Economics, 2014.

Myerson, Roth B. "Perspectives on Mechanism Design in Economic Theory". American Economic Review, 98, 3 (2008), 586-603. Nobel Lecture Prize do dia 8 de dezembro de 2007. doi:10.1257/aer.98.3.586.

Peters, Ole. "The time resolution of the St Petersburg paradox". Philosophical Transactions of Royal Societya. A.; 369, 1956 (2011), 4913-4931.

Quiggin, John. Zombie economics: How dead ideas still walk among us. Princeton: Princeton University Press, 2010.

Quiggin, John. Economics in Two Lessons: Why Markets Work So Well, and Why They Can Fail So Badly. Princeton, NJ: Princeton University Press, 2019.

Rajan, Raghuram G. "Has Finance Made the World Riskier?" European Financial Management, 12, 4 (2006), 499-533. doi:10.1111/j.1468-036x.2006.00330.x 
Raz, Joseph. The Morality of Freedom. Oxford: Clarendon Press, 1986.

Roubini, Nouriel. "Why Central Banks Should Burst Bubbles". International Finance, 9, 1 ()2006, 87-107. doi:10.1111/j.1468-2362.2006.00032.x

Sandri, Serena. Reflexivity in Economics: an experimental examination on the selfreferenciality in economic theories. Heidelberg: Physica-Verlag, 2009.

Schefczyk, Michael. "Financial Markets: Applying Argument Analysis to the Stabilisation Task". In: Hansson S.; Hirsch Hadorn G. (eds). The Argumentative Turn in Policy Analysis. Logic, Argumentation \& Reasoning (Interdisciplinary Perspectives from the Humanities and Social Sciences), vol 10. Springer, Cham, 2016.

Schelling, T. C. (1983). "Ethics, Law, and the Exercise of Self-Command". Tanner Lecture on Human Values, na University of Michigan, em 19 e 21 de março de 1982. Available at: <https://tannerlectures.utah.edu/_documents/a-toz/s/schelling83.pdf >

Sorensen, Roy A. Blindspots. New York, NY: Oxford University Press, (1988).

Sorensen, Roy A. "Infinite 'Backward' Induction Arguments". Pacific Philosophical Quarterly, 80, 3 (1999), 278-283. doi:10.1111/1468-0114.00084

Sorensen, Roy A. Vagueness and Contradiction. Oxford, UK: Clarendon Press, 2001.

Sorensen, Roy A. "Epistemic Paradoxes". The Stanford Encyclopedia of Philosophy (Spring 2014 Edition), Edward N. Zalta (ed.), 2014. Available at: https://plato.stanford.edu/archives/spr2014/entries/epistemic-paradoxes/

Soros, George. The New Paradigm for Financial Markets: The Credit Crisis of 2008 and What It Means. New York: Public Affairs, 2008.

Stiglitz, Joseph E. Freefall: America, free markets, and the sinking of the world economy. New York: W.W. Norton \& Co, 2010.

Sunstein, Cass R. Infotopia: how many minds produce knowledge.New York: Oxford University Press, 2006.

Talwalkar, Presh. The joy of game theory: An introduction to strategic thinking. Chicago: P. Talwalkar, 2014, (e-book).

Tetlock, Phillip; Gardner, Dan. Superforecasting: art and science of prediction. New York: Crown Publishers, 2016.

Tucker, Paul. Unelected Power: The Quest for Legitimacy in Central Banking and the Regulatory State. Princeton: Princeton University Press, 2018.

Walter, Christian. "Éthique et finance: le tournant performatif", Transversalités 124, 2012/4 124, 29-42. doi:10.3917/trans.124.0029 
Walter, Christian. "Les deux quantifications de la théorie financière. Contribution à une histoire critique des modèles financiers". Working Paper 85, February 2015. Paris: Foundation Maison des Sciences de l'Homme. Available at: <halshs-01118147>. 